Revista Brasileira de Agricultura Irrigada v.13, nº.1, p. 3180 - 3189, 2019

ISSN 1982-7679 (On-line)

Fortaleza, CE, INOVAGRI - http://www.inovagri.org.br

DOI: $10.7127 /$ rbai.v13n100842

Protocolo 842.19 - 19/12/2017 Aprovado em 02/04/2019

\title{
PRODUÇÃO DO FEIJÃO-VAGEM SUBMETIDO A DIFERENTES TENSÕES DE ÁGUA NO SOLO
}

\author{
Laura Dias Ferreira ${ }^{1}$, Chaiane Guerra da Conceição ${ }^{2}$, Ana Rita Costenaro Parizi ${ }^{3}$, Luciane Maciel
} Arce $^{4}$, Giulian Rubira Gauterio ${ }^{5}$

\begin{abstract}
RESUMO
A água é um dos principais fatores que limitam o rendimento das plantas, sendo a prática da irrigação extremamente importante, principalmente quando as culturas são conduzidas em ambientes protegidos, uma vez que a reposição da demanda hídrica da planta, ocorre exclusivamente por meio desta. O manejo de irrigação com base na tensiometria vem sendo largamente utilizada, porém, para cada região existe uma recomendação da tensão crítica para planta, sendo que para a região de Alegrete, RS, e para a cultura estudada, esta ainda é desconhecida. Este estudo teve como objetivo testar diferentes tensões de água no solo na produção final da cultura do feijão-vagem. $\mathrm{O}$ trabalho foi desenvolvido em ambiente protegido da Universidade Federal do Pampa - Campus Alegrete, no período de março a maio de 2017, sendo utilizada a cultivar Macarrão Baixo Belo. O trabalho foi conduzido em vasos plásticos, composto por cinco tratamentos $(30,40,50,60$ e $70 \mathrm{kPa})$ e quatro repetições. As irrigações foram realizadas conforme as diferentes tensões, e a lâmina foi determinada conforme a evapotranspiração da cultura (ETc), estimada pelo método do Tanque Classe A. Ao final do ciclo da cultura, foi determinado o componente de produtividade final de vagens $\left(\mathrm{kg} \mathrm{ha}^{-1}\right)$. Através dos resultados obtidos, observou-se que a produção de vagens sofreu influência direta da irrigação, apresentando resultados positivos e expressivos nas menores tensões $(30,40$ e $50 \mathrm{kPa})$, sendo que o tratamento de $30 \mathrm{kPa}$ apresentou a melhor produtividade com média de 9.995,75 $\mathrm{kg} \mathrm{ha}^{-1}$.
\end{abstract}

Palavras-chave: Phaseolus vulgaris L., manejo de irrigação, tensiometria, ambiente protegido

\section{SNAP BEAN PRODUCTION SUBMITTED TO DIFFERENT SOIL WATER TENSIONS}

\footnotetext{
1 Mestranda em Engenharia Agrícola, Universidade Federal de Santa Maria, Santa Maria, Brasil. E-mail: lauradiasferreira14@gmail.com

${ }^{2}$ Professora, Instituto Federal de Educação, Ciência e Tecnologia do Rio Grande do Sul, Sertão, Rio Grande do Sul, Brasil. E-mail: chaianepg@yahoo.com.br

${ }^{3}$ Professora, Instituto Federal de Educação, Ciência e Tecnologia Farroupilha, Alegrete, Rio Grande do Sul, Brasil. E-mail: ana.parizi@iffarroupilha.edu.br

${ }^{4}$ Graduanda em Engenharia Agrícola, Universidade Federal do Pampa/Instituto Federal de Educação, Ciência e Tecnologia Farroupilha, Alegrete, Rio Grande do Sul, Brasil. E-mail: luciane.eng.agricola@ gmail.com

5 Engenheiro Agrícola, Universidade Federal do Pampa, Alegrete, Rio Grande do Sul, Brasil. E-mail: giugauterio@gmail.com
} 


\begin{abstract}
Water is one of the main factors limiting the yield of plants, with irrigation being extremely important, especially when the crops are conducted in protected environments, since the replenishment of the water demand of the plant occurs exclusively through this. Irrigation management based on tensiometry has been widely used, however, for each region there is a recommendation of the critical plant stress, and for the region of Alegrete, RS, and for the culture studied, this is still unknown. This study had as objective to test different soil water stresses in the final production of the snap bean culture. The work was carried out in a greenhouse at the Federal University of Pampa - Alegrete Campus, from March to May 2017, using the cultivar Macarrão Baixo Belo. The work was conducted in plastic containers, composed of five treatments $(30,40,50,60$ and $70 \mathrm{kPa})$ and four replicates. Irrigations were carried out according to the different stresses, and the leaf was determined according to crop evapotranspiration (ETc), estimated by the Class A tank method. At the end of the crop cycle, the final snap bean production component was determined $\left(\mathrm{kg} \mathrm{ha}^{-1}\right)$. It was observed that snap bean production was directly influenced by irrigation, presenting positive and expressive results in the lower strains $(30,40$ and $50 \mathrm{kPa})$, with the $30 \mathrm{kPa}$ treatment presenting the best productivity with an average of $9,995.75 \mathrm{~kg} \mathrm{ha}^{-1}$.
\end{abstract}

Keywords: Phaseolus vulgaris L., irrigation management, tensiometry, protected environment

\section{INTRODUÇÃO}

O feijão-vagem (Phaseolus vulgaris L.), da mesma espécie do feijão de grãos secos, pertence à família das leguminosas e apresenta alta fonte de proteína para nutrição humana, apresentando diferença para os demais, no que diz respeito às suas partes constituintes, que podem ser totalmente comestíveis (MOREIRA et al., 2009).

O feijão-vagem apresenta textura macia e sem fibras, variando comprimento de 15 a 18 $\mathrm{cm}$. A parte terminal de sua haste define os dois modos de crescimento, sendo o primeiro definido como anão, rasteiro ou arbustivo, podendo atingir altura média de $50 \mathrm{~cm}$, com florescimento e produção de vagens centralizados em um curto período de tempo. Já no segundo, o crescimento é indeterminado (feijão-vagem trepador), necessitando do monitoramento de suas hastes, que podem chegar a $2,5 \mathrm{~m}$, sendo as vagens produzidas em períodos mais extensos, apresentando maior produtividade que $o$ feijão-vagem anão (TRANI et al., 2015).

A produção da cultura vem crescendo, e apesar de ser cultivado basicamente por pequenos produtores, vem ganhando espaço no mercado. A semeadura pode ocorrer em três épocas, a primeira no período de agosto a dezembro (regiões como no Sul); a segunda entre os períodos de janeiro a abril (todo o país); e a terceira, no período de maio a agosto (regiões no Centro-Oeste) (VIEIRA et al., 2011).

Uma das diferenças entre a produção agrícola para os demais setores da economia está a exposição da cultura às condições climáticas (SILVA, 2011), sendo a agricultura considerada uma atividade de alto risco, por não se ter o controle sobre os elementos climáticos (ROMANINI et al., 2010). Neste contexto, o cultivo em ambiente protegido se destaca por proporcionar um ambiente mais controlado (MARY et al., 2007). Além disso, o uso desta técnica possibilita o cultivo de várias culturas fora de época e aumentando as chances de sucesso nessa atividade (SANTOS, 2016).

No Rio Grande do Sul (RS), a cultura do feijão-vagem prioriza-se por cultivo a céu aberto, na primavera e no outono. Porém, como o estado apresenta, nesta época, baixa radiação solar e temperatura, e excesso de chuvas, estes fatores limitam a produção da cultura em ambiente externo (FELTRIM et al., 2006).

Deste modo, parte dessas limitações podem ser reduzidas com o cultivo em ambiente protegido, controlando a temperatura, umidade e chuva, impedindo a queda de flores, apodrecimento de raízes, molhamento foliar e 
incidência de doenças (HELDWEIN et al., 2010).

A adoção de técnicas racionais de manejo conservacionista do solo e da água tem grande importância para a sustentabilidade, uma vez que de forma econômica possa manter ao longo do tempo esses recursos com quantidade e qualidade suficientes para a manutenção de níveis satisfatórios de produtividade (WUTKE et al., 2000).

$\mathrm{Na}$ adoção do manejo de água via solo, este pode ser baseado no potencial de água no solo, utilizando-se da tensiometria, podendo aumentar a rentabilidade da cultura (PAVANI et al., 2008). De acordo com Braga e Calgaro (2010), o tensiômetro mede a tensão de água no solo ou o potencial matricial, podendo ser convertido para teor de água, obtendo-se o teor de água atual no solo, na profundidade desejada. O tensiômetro apresenta algumas limitações, porém é utilizado de forma significativa e com resultados satisfatórios (BAKKER et al., 2007).

No manejo de água via clima, segundo Contin (2008), o Tanque Classe A é um dos métodos de estimativa da evapotranspiração de referência mais utilizado, devido à praticidade ao manuseio e baixo custo de instalação e manutenção.

Diante desse contexto, o estudo teve como objetivo testar diferentes tensões de água no solo, na produtividade final da cultura do feijão-vagem.

\section{MATERIAL E MÉTODOS}

O trabalho foi desenvolvido na Universidade Federal do Pampa - Campus Alegrete - Rio Grande do Sul. O Município de Alegrete localiza-se geograficamente a uma latitude de $29^{\circ} 47^{\prime} 01,63^{\prime \prime}$ Sul e a uma longitude de 55 47'27,54" Oeste. O local se encontra a $121 \mathrm{~m}$ acima do nível do mar, apresentando clima predominante subtropical, temperado quente, com estações bem definidas (Cfa na classificação de Koppen), com precipitação pluviométrica média de $1525 \mathrm{~mm}$ anuais.

O trabalho foi conduzido em ambiente protegido, com localização no sentido Leste Oeste, confeccionado por material plástico convencional de 150 micra, apresentando dimensões de 7 x 15 m, com bancadas também orientadas no mesmo sentido.

Foram utilizados vasos plásticos com capacidade de vinte litros com $33 \mathrm{~cm}$ de diâmetro e $30 \mathrm{~cm}$ de altura e área de $0,0855 \mathrm{~m}^{2}$, dispostos em uma bancada com $30 \mathrm{~cm}$ de distância em relação ao solo. Os vasos foram preenchidos com solo oriundo de um Argissolo Vermelho distrófico arênico, unidade de mapeamento São Pedro (STRECK et al., 2008).

O delineamento experimental utilizado foi inteiramente casualizado composto por cinco tratamentos, representados pelas diferentes tensões de 30, 40, 50, 60 e $70 \mathrm{kPa}$ (BRITO et al., 2015) com quatro repetições cada.

A semeadura foi realizada manualmente no dia 20 de março de 2017, sendo utilizada a cultivar Macarrão Baixo Belo com ciclo médio de 55 a 60 dias. Utilizaram-se na semeadura nove sementes por vaso, e após um período de crescimento de aproximadamente 20 dias após a emergência (DAE), foi realizado o desbaste, permanecendo somente 3 plantas por vaso, representando uma população de planta de 350.795 plantas $\mathrm{ha}^{-1}$. Para o manejo da irrigação, determinando-se o quando irrigar, se deu através da utilização de tensiômetros, os quais foram instalados a $8 \mathrm{~cm}$ de profundidade no solo dos vasos. Deste modo, o turno de rega ficou variado com intervalos de até sete dias entre as irrigações, nos diferentes tratamentos, conforme a tensão de cada um dos mesmos.

As lâminas de irrigação aplicadas durante o ciclo da cultura, basearam-se nos dados de evaporação do Tanque Classe A, localizado no interior do ambiente protegido.

O cálculo da lâmina de irrigação se deu pela equação 1 (DOORENBOS; PRUITT, 1977): 


$$
\mathrm{ETc}=\mathrm{Ev} \cdot \mathrm{Kp} \cdot \mathrm{Kc}
$$

Em que:

ETc - Evapotranspiração da cultura (mm);

$\mathrm{Ev}$ - Evaporação do tanque (mm);

$\mathrm{Kp}$ - Coeficiente do tanque (admensional);

Kc - Coeficiente de cultura;

Para a variável número de vagens por planta (NVP), foram coletadas ao final do ciclo da cultura, todas as vagens das três plantas por cada vaso para ambos os tratamentos $\mathrm{e}$ realizada a contagem.
Já a variável massa fresca de vagens por planta (MFV), coletou-se em cada tratamento, todas as vagens correspondentes à cada planta e realizou-se a pesagem individual das vagens de cada planta e fez-se a soma.

Quando as plantas atingiram a maturidade fisiológica, o componente de produção avaliado foi a produtividade de vagem em $\mathrm{Kg}$ ha ${ }^{-1}$, conforme a equação 2 .

$$
\operatorname{PFV}\left(\mathrm{Kg} \mathrm{ha}^{-1}\right)=\frac{(\text { prod } . \times 1000)}{A_{v}} \times 10000
$$

Em que:

PFV-produtividade final de vagens em $\mathrm{Kg} \mathrm{ha}^{-1}$; Prod. - produção de vagens em gramas;

$\mathrm{A}_{\mathrm{v}}$ - área do vaso em $\mathrm{m}^{2}$;

Para a interpretação dos resultados, foi realizada a análise de variância utilizando o Teste $\mathrm{F}$ ao nível de $5 \%$ de probabilidade de erro. Para interpretação do nível de significância, utilizou-se o programa de software Sisvar 5.6.

\section{RESULTADOS E DISCUSSÃO}

A Figura 1 apresenta a aplicação das lâminas de água $(\mathrm{mm})$ aplicada ao longo do ciclo da cultura do feijão-vagem para as diferentes tensões de água no solo. A média de água aplicada foi de $54,32 \mathrm{~mm}$, e o número de irrigações realizadas entre os tratamentos foi de $42,39,34,19$ e 13, para os tratamentos com 30, 40, 50, 60 e $70 \mathrm{kPa}$, respectivamente. 


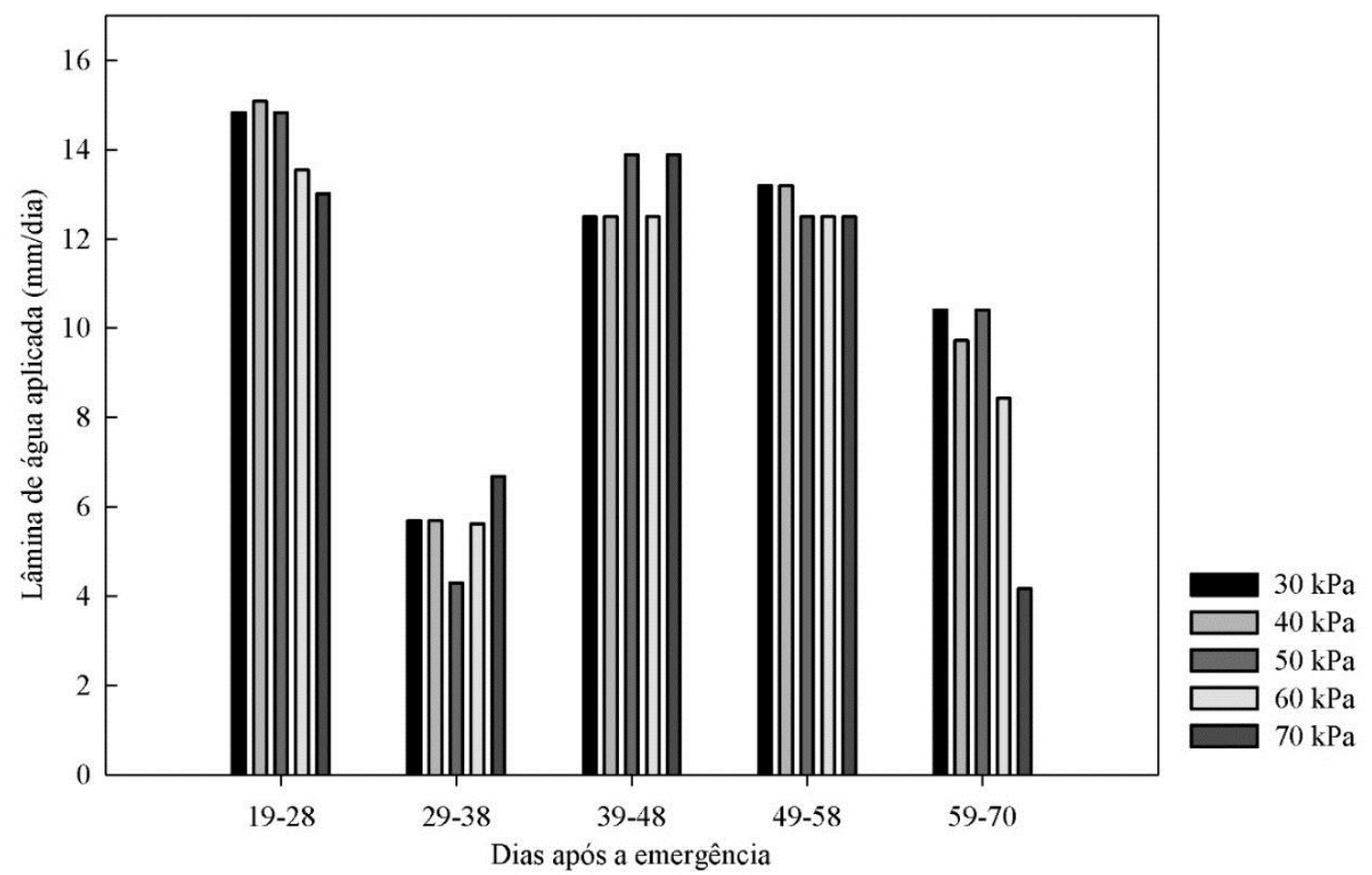

Figura 1. Aplicação das lâminas de água ( $\mathrm{mm} / \mathrm{dia})$ no ciclo da cultura do feijão-vagem conforme os dias após emergência (DAE).

Nos tratamentos de 30, 40 e $50 \mathrm{kPa}$, conforme os dez primeiros dias de irrigações (19 - 28 DAE), a demanda hídrica aplicada foi maior, recebendo lâminas mais altas e em períodos com intervalos menores, em função da baixa tensão de água no solo. A reposição da demanda hídrica em espaços de tempo reduzido, contribuiu para que o crescimento e produtividade das tensões menores fossem ao final do ciclo maiores comparado aos demais.

Em contrapartida, as tensões maiores representadas por 60 e $70 \mathrm{kPa}$ receberam lâminas maiores em alguns casos (29 - 38 DAE) devido ao somatório da evapotranspiração da cultura (ETc) dos dias não irrigados, em função do intervalo maior da reposição da lâmina. Estes intervalos de tempo maiores contribuíram para que as plantas fossem sujeitas a um déficit hídrico seguido da baixa produtividade.

Na Tabela 1, é apresentado o resumo da análise de variância referente aos componentes da produção e produtividade final de vagens do feijão.

Tabela 1. Resumo da análise de variância do número de vagens por planta (NVP), massa fresca de vagens por planta (MFV) e produtividade final de vagens (PFV) conforme as diferentes tensões de água no solo na cultura do feijão-vagem.

\begin{tabular}{ccccc}
\hline \multirow{2}{*}{ FV } & \multirow{2}{*}{ GL } & \multicolumn{3}{c}{ Quadrados médios } \\
\cline { 3 - 5 } & & NVP & MFV & PFV \\
\hline Tensões & 4 & $15,57500^{*}$ & $317,90675^{*}$ & $27176732.0619^{* *}$ \\
Resíduo & 15 & 3,88333 & 35,97033 & 2455265.40436 \\
CV (\%) & & 51,18 & 36,73 & 26,10 \\
Média Geral & & 4,30 & 13,10 & 6003.07 \\
\hline
\end{tabular}

*: significativo ao teste $\mathrm{F}$ ao nível de 5\% de significância; **: significativo ao teste $\mathrm{F}$ ao nível de $1 \%$ de significância; ns: não significativo ao teste $\mathrm{F}$ ao nível de 5\% de significância.

De acordo com a Tabela 1 observa-se que o número de vagens por planta, massa fresca de vagens e a produtividade final de vagens apresentou diferença estatística significativa entre os tratamentos. 
Na figura 2, observa-se que o número de vagens por planta ajustou-se em uma função polinomial quadrática, apresentando o maior pico de produção deste parâmetro no tratamento de $40 \mathrm{kPa}(5,50)$, decrescendo conforme o aumento da tensão.de água no solo.

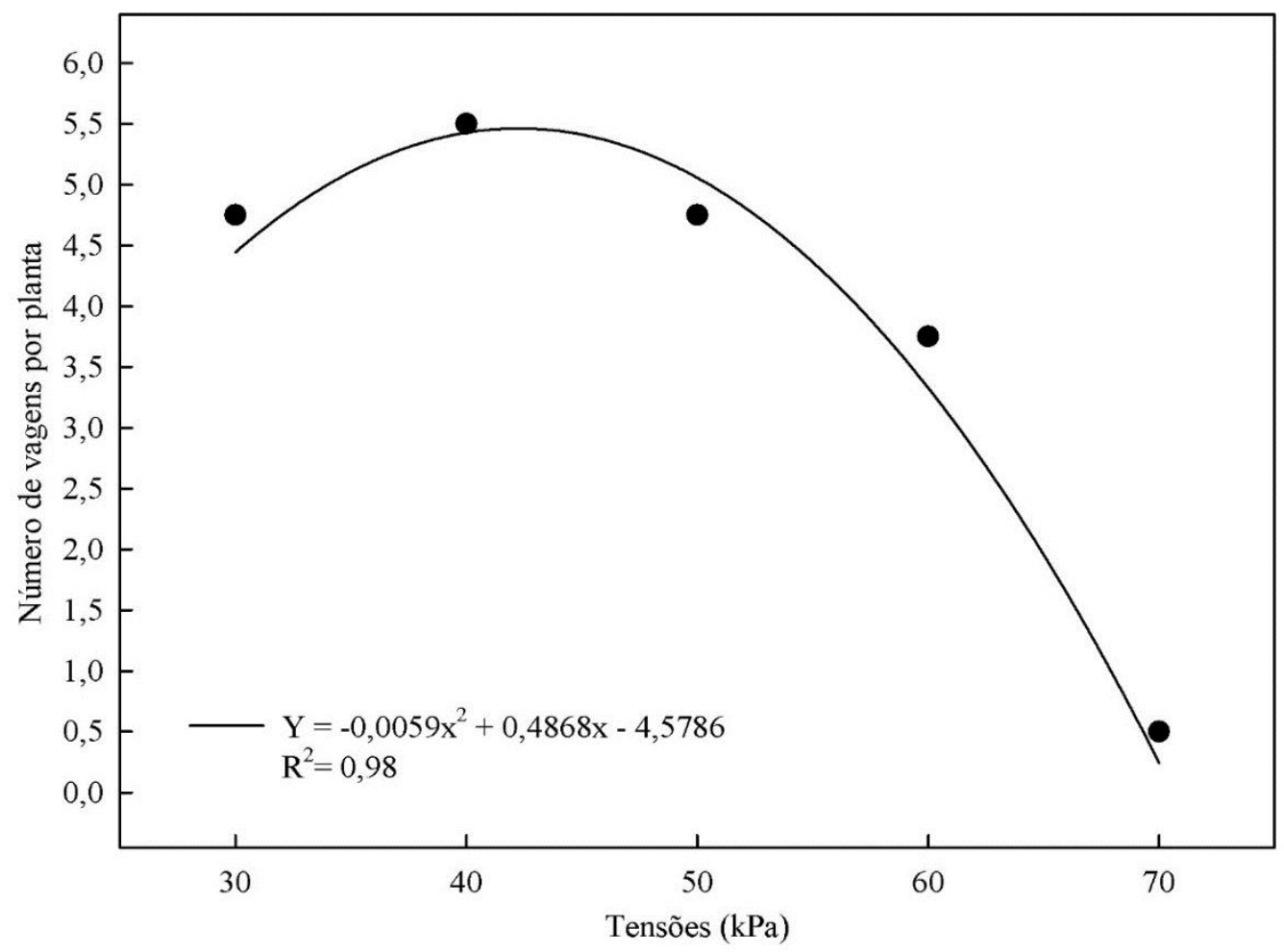

Figura 2. Comportamento do número de vagens por planta (NVP) para as cinco tensões de água no solo. Alegrete, RS.

Com relação às maiores tensões (60 e $70 \mathrm{kPa})$ em que o número de vagens por planta obteve baixa produção, ambas as plantas destes tratamentos passaram por um déficit hídrico, recebendo baixa lâmina de água, levando a decrescer de forma significativa os resultados. Nascimento et al. (2004), ao avaliar o efeito da variação de níveis de água disponível no solo para o crescimento e produção do feijão-caupi, verificou que a cultura sofreu influência direta devido a restrição hídrica, diminuindo a produção do número de vagens por planta.

Ainda analisando os resultados, os mesmos corroboram com os de Miranda e Belmar (1977) e Stone et al. (1988), onde ambos observaram também, que o número de vagens por planta em feijoeiros reduziu quando submetidos a um déficit hídrico.
Miranda et al. (2000) e Nóbrega et al. (2004) também verificaram que o aumento do estresse hídrico resultou na baixa produção do feijão cultivar carioca, para as condições de solo do cerrado e do agreste paraibano, respectivamente. Conceição et al. (2017) estudando a influência de diferentes lâminas de irrigação sobre a produção do feijão comum conduzido na $2^{\mathrm{a}}$ safra, verificou em seu estudo, que a produção do número de vagens por planta foi maior no tratamento com maior disponibilidade hídrica.

A Figura 3, apresenta a massa fresca de vagens por planta, onde foi observado um comportamento polinomial cúbico, indicando maior valor para a tensão de $30 \mathrm{kPa}$, ocorrendo o decréscimo na massa fresca de vagens por planta conforme o aumento da tensão. 


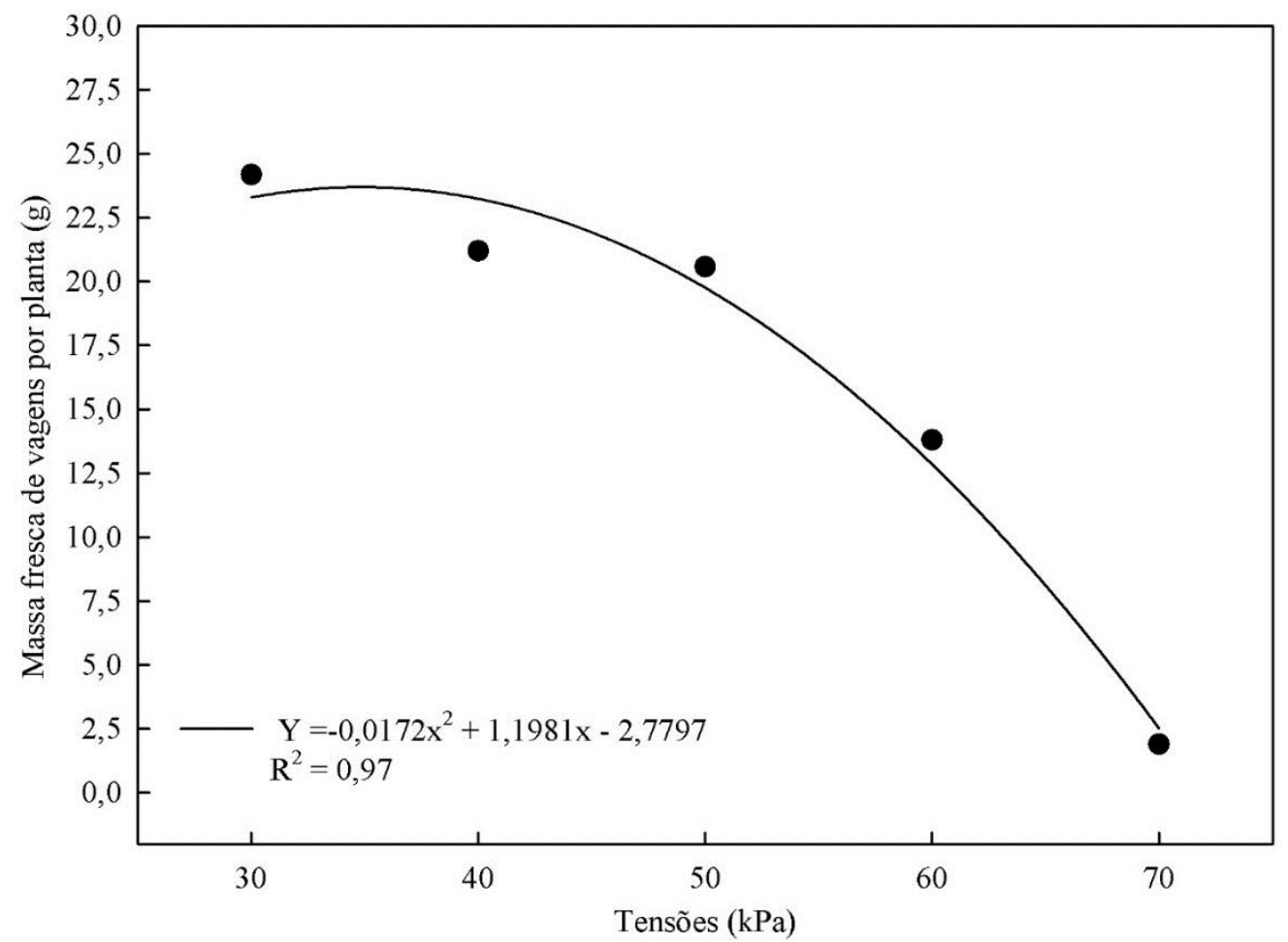

Figura 3. Comportamento da massa fresca de vagem por planta (g) para as cinco tensões de água no solo. Alegrete, RS.

Segundo a análise dos resultados, a Figura 3 mostra que as menores tensões de 30, 40 e $50 \mathrm{kPa}$ apresentaram os maiores valores para o componente em análise, evidenciando que ao longe do aumento da tensão de água no solo a produtividade da massa fresca de vagens por planta decresceu de forma significativa.

De acordo com SILVA et al. (2012), analisando a massa fresca de vagens do feijãode-metro, verificou que o comportamento da redução da massa fresca de vagens ocorreu quando se sucedeu a diferenciação no manejo de irrigação realizada na fase produtiva com relação aos diferentes potenciais matriciais testados, ou seja, nos maiores potenciais, obteve-se menores produções.

Conforme o aumento da tensão, as plantas conduzidas nas tensões de 60 e $70 \mathrm{kPa}$ na fase produtiva receberam lâminas menores de irrigação, o que levou aos resultados se assemelharem aos de SILVA et al. (2012) que ao final do ciclo da cultura também adquiriu redução da massa fresca de vagens. Este cenário foi decorrente das lâminas baixas aplicadas em períodos prolongados, e do déficit hídrico em que as plantas foram submetidas.

A produtividade final de vagens pode ser observada na Figura 4, onde é possível perceber que a cultura se comportou do mesmo modo que a massa fresca das vagens, apresentando maior valor no tratamento de $30 \mathrm{kPa}$.

A curva ajustada para o parâmetro analisado evidenciou que a cultura atinge seu valor máximo quando a tensão de água no solo correspondeu aos $30 \mathrm{kPa}$.

Relatando sobre as tensões de água no solo, conforme os períodos em que a reposição da lâmina de água era realizada nas tensões de 60 e $70 \mathrm{kPa}$ com intervalores de até 7 dias sem receber a mesma, as plantas foram suscetíveis a um déficit hídrico, recebendo baixa reposição da lâmina e ocasionando na baixa produtividade comparado aos demais tratamentos. 


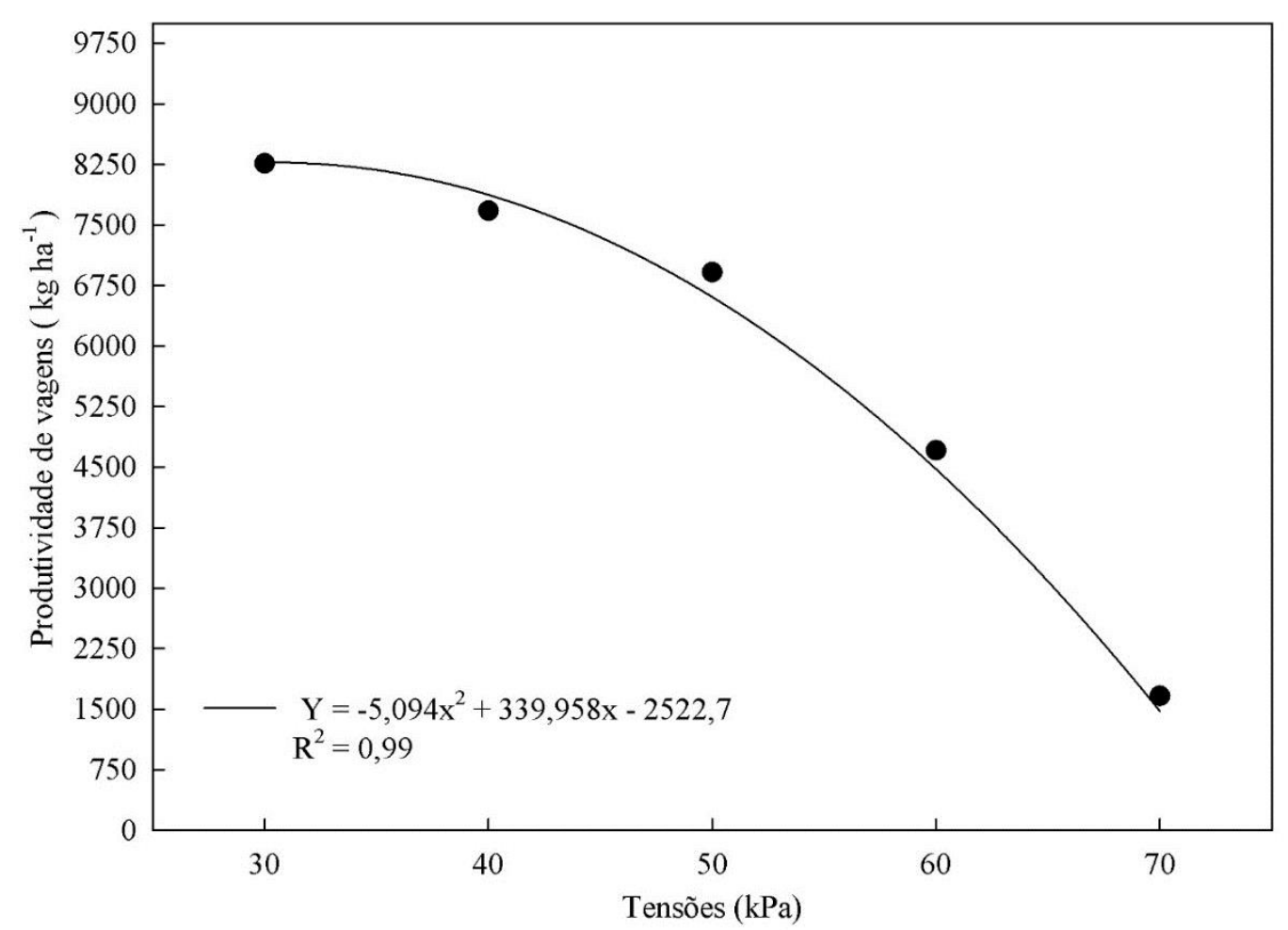

Figura 4. Produtividade final de vagens $\left(\mathrm{Kg} \mathrm{ha}^{-1}\right)$ submetida a diferentes tensões de água no solo conforme o ciclo da cultura do feijão-vagem. Alegrete, RS.

Figuerêdo et al. (2008) estudando tensões de água em solos argilosos em ambiente de Cerrado, verificou que a maior produção ocorreu por meio de irrigações realizadas com o nível do potencial matricial de água no solo em torno de $37 \mathrm{kPa}$, onde seus demais tratamentos correspondentes aos $40 \mathrm{kPa}, 50 \mathrm{kPa}$, $60 \mathrm{kPa}$ e $70 \mathrm{kPa}$ apresentaram resultados em ordem decrescente conforme valores médios de produtividade.

Estes resultados podem ser comparados com o estudo de Conceição et al. (2017), onde relata que a demanda de água está diretamente ligada a interferência que o déficit hídrico causa na fisiologia da planta, consequentemente ocasionado em abscisões nas flores como também nas vagens, interferindo na redução da produtividade final.

Em seu estudo, Brito et al. (2015), testando diferentes níveis de depleção e potencial matricial do solo de textura média na produtividade do feijoeiro, obteve que a tensão de $30 \mathrm{kPa}$, concedeu a maior produtividade de grãos do feijoeiro.

\section{CONCLUSÕES}

A tensão recomendada para a região de Alegrete - RS na condução da cultura do feijãovagem cultivado em ambiente protegido é representada pelos $30 \mathrm{kPa}$.

De acordo com os resultados, tensões mais elevadas acarretam num déficit hídrico para a cultura estudada, devido aos períodos prolongados sem a reposição da lâmina de irrigação. Deste modo, a tensão de $30 \mathrm{kPa}$ resultou na maior produtividade de vagens comparada às demais.

\section{REFERÊNCIAS BIBLIOGRÁFICAS}

BAKKER, G.; van der PLOEG, M.J.; DE ROOIJ, G.H.; HOOGENDAM, C.W.; GOOREN, H. P.A.; HUISKES, C.; KOOPAL, L.K. \& KRUIDHOF, H. New polymer tensiometers: Measuring matric pressures down to the wilting point. Vadose Zone Journal, v. 6, n. 1, p. 196-202, 2007. DOI: 10.2136/vzj2006.0110. 
BRAGA, M. B.; CALGARO, M. Uso da tensiometria no manejo da irrigação. Petrolina: Embrapa Semiárido, 2010. 30 p. (Embrapa Semiárido. Documentos, 235).

BRITO, R. R; FILHO, H. G.; SAAD, J. C. C.; OLIVEIRA, S. R. M. Produtividade do feijoeiro sob diferentes potenciais matriciais e fatores de depleção da água no solo. Nativa, v. 3, n. 2, p. 109-114, 2015. http://dx.doi.org/10.14583/2318-

7670.v03n02a06.

BRITO, R. R.; FILHO, H. G.; SAAD, J. C. C.; OLIVEIRA, S. R. M.; RIBEIRO, H. P. Níveis de depleção e potencial matricial do solo de textura média na produtividade do feijoeiro. Revista Brasileira de Agricultura Irrigada-RBAI, v. 9, n. 5, p. 300-309, 2015. DOI: $10.7127 /$ rbai.v9n500317.

CONCEIÇÃO, C. G.; PARIZI, A. R. C.; GOMES, A. C. S.; BITENCOURT, G. B.; CONCEIÇÃO, J. A. Influência de lâminas de irrigação sobre a produção do feijão comum conduzido na $2^{\text {a }}$ safra. Revista Brasileira de Agricultura Irrigada-RBAI, v. 11, n. 6, 2017. DOI: 10.7127/RBAI.V11N600645.

\section{CONTIN, F. S. Tecnologia do irrigâmetro} aplicada no manejo da irrigação do feijoeiro. 2008. 64f. Dissertação (Mestrado em Engenharia Agrícola) - Universidade Federal de Viçosa, Minas Gerais.

DOORENBOS, J.; PRUITT, W.O. Guidelines for predicting crop water requirements. Rome: FAO, 1977. 179 p.

FIGUERÊDO, S. F.; POZZEBON, E. J.; FRIZZONE, J. A.; AZEVEDO, J. A.; GUERRA, A. F.; SILVA, E. M. Potencial mátrico de Água no Solo para Maiores Lucratividades do Feijoeiro Irrigado em Ambiente de Cerrado. Planaltina: Embrapa Cerrados, 2008. 6 p. (Comunicado Técnico, 150).

FELTRIM, A.L.; FILHO, A. B. C.; REZENDE, B L. A.; BORBOSA, J. C.
Produção de chicória em função do período de cobertura com tecido de polipropileno. Horticultura Brasileira, v. 24, n. 2, p. 249254, 2006. http://dx.doi.org/10.1590/S010205362006000200027.

HELDWEIN, A. B.; STRECK, N. A.; STURZA, V. S.; LOOSE, L. H.; ZANON, A. J.; TOEBE, M.; SOUZA, A. T.; PETERS, M. B.; KARLEC, F. Plastocrono e rendimento de feijão-de-vagem cultivado sob ambiente protegido e no ambiente externo em semeadura tardia no outono. Ciência Rural, v. 40, n. 4, p. 768-773, 2010 . http://dx.doi.org/10.1590/S010384782010005000045.

MARY, W.; KENMOCHI, C. S.; COMETTI, M. N.; LEAL, P. A. M. Avaliação de estrutura de bambu como elemento construtivo para casa de vegetação. Engenharia Agrícola, v. 27, n.1, p.100-109, 2007. http://dx.doi.org/10.1590/S010069162007000100003.

MIRANDA, L. N.; AZEVEDO, J. A.; MIRANDA, J. C. C.; GOMES, A. C. Produtividade do feijoeiro em resposta a adubação fosfatada e a regimes de irrigação em solo de Cerrado. Pesquisa Agropecuária Brasileira, v. 35, n. 4, p. 703-710, 2000.

MIRANDA, N.O.; BELMAR, N.C. Déficit hídrico y frecuencia de riego en frijol (Phaseolus vulgaris L.). Agricultura Técnica, v.37, n.3, p.111-117, 1977.

MOREIRA, R. M. P.; FERREIRA, J. M.; TAKAHASHI, L. S. A.; VASCONCELOS, M. E. C.; GEUS, L. C.; BOTTI, L. Potencial agronômico e divergência genética entre genótipos de feijão-vagem de crescimento determinado. Semina, v. 30, n. 1, p. 1051-1060, 2009.

DOI: $10.5433 / 1679-$

0359.2009v30n4Sup1p1051.

NASCIMENTO, J. T.; PEDROSA, M. B.; TAVARES SOBRINHO, J. Efeito da variação de níveis de água disponível no solo sobre o crescimento e produção de feijão caupi, vagens 
e grãos verdes. Horticultura Brasileira, v. 22, n. 2, p. 174-177, 2004. http://dx.doi.org/10.1590/S010205362004000200002 .

NÓBREGA, J. Q.; RAO, T. V. R.; BELTRÃO, N. E. M.; FIDELES FILHO, J. Avaliação do efeito do estresse hídrico no rendimento do feijoeiro por sensoriamento remoto termal. Revista Brasileira de Agrometeorologia, v. 12, n. 2, p. 299-305, 2004.

PAVANI, L. C.; LOPES, A. S.; GALBEIRO, R. B. Manejo da irrigação na cultura do feijoeiro em sistemas plantio direto e convencional. Engenharia Agrícola, v. 28, n. 1, p. 12-21, 2008. http://dx.doi.org/10.1590/S010069162008000100002.

ROMANINI, C. E. B.; GARCIA, A. P.; ALVARADO, L. M.; CAPPELLI, N. L.; UMEZU, C. K. Desenvolvimento e simulação de um sistema avançado de controle ambiental em cultivo protegido. Revista Brasileira de Engenharia Agrícola e Ambiental, v.14, n. 11, p. 1193-1201, 2010. http://dx.doi.org/10.1590/S141543662010001100009.

SANTOS, D. Variabilidade produtiva, tamanho de parcela e uso de bordaduras em experimentos com culturas olerícolas em ambiente protegido. 2016. 66 f. Tese (Doutorado em Agronomia) - Universidade Federal de Santa Maria.

SILVA, W. G. Manejo de irrigação para o feijão-de-metro cultivado em ambiente protegido. 2011. 97f. Tese (Doutorado em Engenharia Agrícola) - Universidade Federal de Lavras. Lavras, Minas Gerais.

SILVA, W. G.; CARVALHO, J. A.; OLIVEIRA, E. C.; REZENDE, F. C.; JUNIOR,
J. A. L.; RIOS, G. F. A. Manejo de irrigação para o feijão-de-metro, nas fases vegetativa e produtiva, em ambiente protegido. Revista Brasileira de Engenharia Agrícola e Ambiental. v.16, n.9, p.978-984, 2012. http://dx.doi.org/10.1590/S141543662012000900008.

STONE, L. F.; MOREIRA, J. A. A.; SILVA, S. C. Efeitos da tensão de água do solo sobre a produtividade e crescimento do feijoeiro. Pesquisa Agropecuária Brasileira, v. 23, n. 2, p. 161-167, 1988.

STRECK, E. V. KÄMPF, N.; DALMOLIN, R. S. D.; KLAMT, E.; NASCIMENTO, P. C. do; SCHNEIDER, P.; GIASSON, E.; PINTO, L. F. S.. Solos do Rio Grande do Sul. 2. ed. Porto Alegre: EMATER, 2008. 222 p.

TRANI, P. E.; PASSOS, F. A.; PEREIRA, J. E.; SEMIS, J. B. Calagem e adubação do feijão-vagem, feijão-fava (ou fava-italiana), feijão-de-lima e ervilha torta (ou ervilha-devagem). Instituto Agronômico. Campinas (SP), jun 2015. Disponível em: <http://www.iac.sp.gov.br/imagem_informaco estecnologicas/99.pdf>. Acesso em: 14 out. 2017.

VIEIRA, C; JÚNIOR, T. J. P; BORÉM, A. Feijão. 2 ed. Minas Gerais: Universidade Federal de Viçosa, 2011. 600p.

WUTKE, E.B.; ARRUDA, F.B.; FANCELLI, A.L.; PEREIRA， J.C.V.N.A.; SAKAI， E.; FUJIWARA, M.; AMBROSANO, G.M.B. Propriedades do solo e sistema radicular do feijoeiro irrigado em rotação culturas. Revista Brasileira de Ciência do Solo, $\quad$ v. 24, $\quad$ n. 3, p. $621-633, \quad$ 2000. 6832000000300015.http:// dx.doi.org/10.1590/

S0100-06832000000300015 